\title{
Transient Left Ventricular Filling Abnormalities (Diastolic Stunning) After Acute Myocardial Infarction
}

\author{
Brian D. Williamson, MD, Michael J. Lim, BS, and Andrew J. Buda, MD
}

A variety of experimental studies suggest that diastolic left ventricular (LV) function changes after acute myocardial infarction (AMI), but limited data exist on these changes in humans. To assess diastolic filling after AMI, 60 patients underwent Doppler echocardiographic examination within 24 hours of AMI. Of 54 patients who also underwent catheterization, $45(83 \%)$ were successfully reperfused. A subgroup of 17 patients underwent a follow-up Doppler examination at 7 days after infarction, whereas 15 patients with stable exertional angina served as control subjects. There was no significant difference in age, gender, incidence of systemic hypertension or diabetes mellitus, heart rate, mean arterial pressure or severity of coronary artery disease between the infarct and control groups. The infarct group had a lower velocity time integral total $(9.9 \pm 0.4 \mathrm{~cm}$ vs $12.0 \pm 0.9 \mathrm{~cm}, p$ $<0.001)$, a lower velocity time integral $E(5.8 \pm 0.3$ $\mathrm{cm}$ vs $6.8 \pm 0.5 \mathrm{~cm}, p<0.01)$ and a lower velocity time integral $0.333(3.5 \pm 0.4 \mathrm{~cm}$ vs $6.1 \pm 0.5 \mathrm{~cm}$, $p<0.01)$ than the control group. In addition, velocity time integral A/total was significantly greater in the infarction group $(0.44 \pm 0.03$ vs $0.35 \pm 0.04$, p $<0.01$ ) compared to the control group. The follow-up subgroup showed an increase in velocity time integral total $(p<0.01)$, velocity time integral $E(p<0.05)$ and velocity time integral $0.333 /$ total $(p<0.05)$ over the first 7 days after infarction. The final recovery values at 7 days were not significantly different from those of the coronary artery disease group. Patients with Initlal ejection fractions $<\mathbf{4 0} \%$ or anterior infarction had the greatest recovery during the 7-day period. In conclusion, LV filling is further impaired during acute infarction

From the Cardiology Division, Department of Internal Medicine, University of Michigan Medical School, Ann Arbor, Michigan. Michael Lim was supported by a Student Fellowship Grant from the American Heart Association of Michigan, Lathrup Village, Michigan. Manuscript received April 9, 1990; revised manuscript received and accepted June 4, 1990.

Address for reprints: Andrew J. Buda, MD, Cardiology Division, University of Michigan Medical Center, 1500 East Medical Center Drive, Taubman Ctr 3910L, Ann Arbor, Michigan 48109-0366. compared to patients with stable coronary artery disease with the predominant impairment in early diastole. After infarction, filling parameters improve over the first 7 days after AMI, suggesting a recovery of diastolic stunning.

(Am J Cardiol 1990;66:897-903)

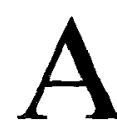
cute myocardial infarction (AMI) is well known to produce impaired systolic function, whereas reperfusion may attenuate the measured decline in systolic function. ${ }^{1,2}$ The concept of myocardial stunning has been proposed to explain the delayed recovery in systolic myocardial performance after $\mathrm{AMI}^{3}$ The impact of AMI and reperfusion on left ventricular (LV) diastolic performance and the possibility of diastolic stunning is less clear. In this regard, it has been shown that transient myocardial ischemia can result in diastolic filling abnormalities in addition to systolic dysfunction. ${ }^{4,5}$ Furthermore, experimental studies have indicated that AMI leads to abnormal LV stiffness or relaxation that may improve with time. 6,7 The nature and extent of $L V$ diastolic dysfunction in AMI in humans and its potential for recovery remain unsettled. The development of Doppler echocardiography has allowed the noninvasive measurement of diastolic filling, which correlates well with other measures of filling. ${ }^{8}$ Accordingly, this study characterizes Doppler LV filling in patients with AMI compared to patients with stable coronary disease and determines if changes in filling occur during the first 7 days after AMI, which may support the existence of diastolic stunning.

\section{METHODS}

These studies were approved by the Human Subjects Review Committee of the University of Michigan Medical School and informed consent was obtained from each patient.

Study group: Pulsed Doppler echocardiograms were performed in 60 patients ( 51 men, 9 women) within 24 hours of admission with AMI as determined by typical history, standard electrocardiographic changes and an increase in cardiac enzymes. No patient had significant valvular heart disease, evidence of mitral regurgitation 
TABLE I Demographics and Clinical Parameters for Patients in the Coronary Artery Disease Control Group, Patients in Acute Myocardial Infarction Group, and Patients in Follow-Up Subgroup

\begin{tabular}{|c|c|c|c|c|}
\hline & $\begin{array}{l}\text { CAD } \\
(n=15)\end{array}$ & $\begin{array}{l}M l \\
(n=60)\end{array}$ & $\begin{array}{l}F / U \\
(n=17)\end{array}$ & $\mathrm{p}$ Value \\
\hline Age (mean) & $56 \pm 9$ & $57 \pm 10$ & $58 \pm 2$ & NS \\
\hline Men & $12(80 \%)$ & $52(87 \%)$ & $12(71 \%)$ & NS \\
\hline Hypertension & $5(33 \%)$ & $31(52 \%)$ & $9(53 \%)$ & NS \\
\hline Diabetes mellitus & $3(20 \%)$ & $14(23 \%)$ & $6(35 \%)$ & NS \\
\hline \multicolumn{5}{|l|}{ Extent of CAD } \\
\hline 1 vessel & $9(60 \%)$ & $33(55 \%)$ & $10(59 \%)$ & NS \\
\hline 2 vessels & $6(40 \%)$ & $17(28 \%)$ & $6(41 \%)$ & NS \\
\hline 3 vessels & $0(0 \%)$ & $4(7 \%)$ & $1(5 \%)$ & NS \\
\hline
\end{tabular}

or cardiogenic shock and all were in a sinus rhythm and had a technically adequate study. Ejection fractions were determined in all patients within 24 hours of admission by radionuclide techniques.

The patients ranged in age from 37 to 76 years (mean 57). All patients developed new $Q$ waves during hospitalization. Thirty-one had a history of systemic hypertension and 14 were known to have diabetes mellitus. Thirty-one patients had anterior AMI and 29 had inferior AMI.

Diagnostic catheterization was performed in 54 patients during the first week after infarction (6 patients refused catheterization). Thirty-three patients had 1vessel disease (defined by a $\geq 70 \%$ narrowing of a major coronary artery or branch), 17 had 2-vessel and 4 had 3 -vessel disease. Forty-five of these 54 patients $(83 \%)$ were successfully reperfused, as determined by an open infarct-related vessel at catheterization.

A subgroup of 17 patients underwent a follow-up Doppler examination 7 days after admission as part of a later phase of patient recruitment. These patients ranged in age from 37 to 76 years (mean 56). Eight patients had inferior AMI while 9 patients had anterior AMI. Serial measurements of systolic function by radionuclide or contrast ventriculography were available in 14 of these patients. There was no difference in age, gender, blood pressure, severity of coronary artery disease, ejection fraction or Doppler filling parameters between these patients and the infarct group as a whole, as listed in Table I.

Control group: Doppler studies were also performed on 15 patients with angiographically documented coronary artery disease (12 men, 3 women). These patients ranged in age from 36 to 74 years (mean 56) and had a history of typical stable exertional angina, $\geq 70 \%$ narrowing of a major coronary artery or large branch, LV ejection fraction of $50 \%$ and no evidence of valve disease. No patient had previous myocardial infarction, as determined by history, electrocardiogram and wall motion analysis. Five patients had a history of systemic hypertension and 3 had diabetes mellitus. Nine patients had 1-vessel and 6 had 2-vessel disease.

Doppler studies: Pulsed-wave Doppler examinations of the $\mathrm{LV}$ inflow were performed with a $2.5-\mathrm{MHz}$
TABLE II Hemodynamics and Peak Filling Velocities for Patients in the Coronary Artery Disease Group and the Acute Myocardial Infarction Group

\begin{tabular}{|llll|}
\hline & $\begin{array}{l}\text { CAD } \\
(n=15)\end{array}$ & $\begin{array}{l}\text { MI } \\
(n=60)\end{array}$ & p Value \\
\hline HR (beats $/ \mathrm{min})$ & $66 \pm 2$ & $80 \pm 3$ & NS \\
MAP $(\mathrm{mm} \mathrm{Hg})$ & $79 \pm 3$ & $85 \pm 2$ & NS \\
Peak $\mathrm{E}(\mathrm{cm} / \mathrm{s})$ & $56 \pm 2$ & $54 \pm 2$ & NS \\
Peak A $(\mathrm{cm} / \mathrm{s})$ & $51 \pm 4$ & $57 \pm 2$ & NS \\
Peak E $/ \mathrm{A}$ & $1.1 \pm 0.1$ & $1.0 \pm 0.1$ & NS \\
\hline CAD $=$ coronary artery disease group; HR = heart rate; MAP = mean arterial \\
pressure; MI = acute myocardial infarction group; NS = not significant. \\
\hline
\end{tabular}

transducer. Using the apical 4-chamber view, the Doppler sample volume $(5 \mathrm{~mm})$ was placed in the mitral valve funnel on the LV side of the mitral anulus. The sample volume was placed as parallel to flow as possible to maximize recorded velocity. ${ }^{9}$ The tracings were recorded on a strip chart recorder at a paper speed of 100 $\mathrm{mm} / \mathrm{s}$.

A digitizing pad and a microcomputer were used to analyze the Doppler wave forms. Wave form analysis was performed by tracing the modal velocity (darkest portion) of each beat and averaging $\geq 3$ consecutive beats. ${ }^{10}$ Peak filling velocities of the early rapid filling wave (E) and the atrial contraction wave (A) as well as the $\mathrm{E} / \mathrm{A}$ ratio were determined. Velocity time integrals, reflecting the area under the wave form, were computed for the total diastolic cycle (velocity time integral total), as well as for early filling (velocity time integral E), late atrial filling (velocity time integral A) and the first onethird of the diastolic cycle (velocity time integral 0.333 ).

Statistical analysis: All results are expressed as mean \pm standard error of the mean. Comparisons were made between the filling parameters and hemodynamics of the infarct group and the coronary artery disease group. Paired comparisons were also made between the acute and follow-up studies in the 7-day follow-up subgroup. A 2-tailed Student's $t$ test was used for all the analyses.

\section{RESULTS}

Comparison of initial filing after infarction to control subjects: The coronary artery disease control group was age- and sex-matched to the AMI group. There was no difference in incidence of diabetes mellitus, systemic hypertension or severity of coronary artery disease between the 2 groups as listed in Table I.

Heart rate and mean arterial pressure were not significantly different between groups. Peak early filling (E), late filling velocity (A) and E/A ratio did not differ significantly between the coronary artery disease and acute infarction groups (Table II). However, there were differences between the velocity time integrals in the infarct group and the coronary artery disease control subjects, as shown in Figure 1. There was a significantly lower total filling integral (velocity time integral total) in the infarct group $(9.9 \pm 0.4 \mathrm{~cm}$ vs $12.0 \pm 0.9$ $\mathrm{cm}, \mathrm{p}<0.001)$, as well as lower early diastolic filling (velocity time integral E; $5.8 \pm 0.3 \mathrm{~cm}$ vs $6.8 \pm 0.5 \mathrm{~cm}$, $\mathrm{p}<0.01)$, and first third velocity time integral $(3.5 \pm$ 
TABLE III Twenty-Four-Hour Doppler Examination Parameters for Patients in the Acute Myocardial Infarction Group Compared to Patients in the Follow-Up Subgroup

\begin{tabular}{|c|c|c|c|}
\hline & $\begin{array}{l}M ! \\
(n=60)\end{array}$ & $\begin{array}{l}F / U \\
(n=17)\end{array}$ & $\rho$ Value \\
\hline PeakE $(\mathrm{cm} / \mathrm{s})$ & $53 \pm 2$ & $5 \pm 5$ & NS \\
\hline Peak $A(\mathrm{~cm} / \mathrm{s})$ & $57 \pm 2$ & $55 \pm 4$ & NS \\
\hline PeakE/A & $1.0 \pm 0.1$ & $0.9 \pm 0.1$ & NS \\
\hline $\operatorname{VTI} E(\mathrm{~cm})$ & $5.8 \pm 0.3$ & $5.1 \pm 0.2$ & NS \\
\hline $\operatorname{VTIA}(\mathrm{cm})$ & $4.4 \pm 0.2$ & $4.2 \pm 0.2$ & NS \\
\hline$V T I E / A$ & $1.6 \pm 0.1$ & $1.4 \pm 0.2$ & NS \\
\hline
\end{tabular}

$0.4 \mathrm{~cm}$ vs $6.1 \pm 0.5 \mathrm{~cm}, \mathrm{p}<0.01)$. The proportion of the late filling to total filling, as measured by velocity time integral $\mathrm{A} /$ total, was significantly greater in the infarct group $(0.44 \pm 0.03$ vs $0.35 \pm 0.04, p<0.01)$, whereas velocity time integral $E /$ total and velocity time integral E/A were not significantly different between the 2 groups.

Of the 54 infarction patients who underwent catheterization, 45 were successfully reperfused. There were no significant differences in peak velocities or velocity time integrals on the acute examinations based on whether reperfusion was successful.

Changes in filling during the first week after infarction: The subgroup of 17 patients with follow-up examinations did not differ significantly from the infarct group as a whole in the clinical parameters of age, gender, systemic hypertension, diabetes mellitus, heart rate, blood pressure or severity of coronary artery disease. Furthermore, the follow-up subgroup had similar Doppler indexes on the 24-hour examination compared to the AMI group as a whole (Table III). Heart rate, mean arterial pressure, peak E, peak $\mathrm{A}$ and peak $\mathrm{E} / \mathrm{A}$ were not significantly changed over the first 7 days, as listed in Table IV. There were, however, significant changes in the velocity time integrals over this time.

Figure 2 shows the changes in mean velocity time integrals from the acute to the follow-up examination. The mean total velocity time integral was depressed
TABLE IV Hemodynamics and Peak Filling Velocities for Patients in the Follow-Up Subgroup

\begin{tabular}{|llll|}
\hline & $\begin{array}{l}\text { AMI } \\
(n=17)\end{array}$ & $\begin{array}{l}F / U \\
(n=17)\end{array}$ & $p$ Value \\
\hline HR (beats $/ \mathrm{min})$ & $82 \pm 3$ & $76 \pm 2$ & NS \\
MAP $(\mathrm{mm} \mathrm{Hg})$ & $85 \pm 2$ & $83 \pm 2$ & NS \\
Peak E $(\mathrm{cm} / \mathrm{s})$ & $50 \pm 5$ & $55 \pm 3$ & NS \\
Peak A (cm/s) & $55 \pm 4$ & $61 \pm 4$ & NS \\
Peak E $/ \mathrm{A}$ & $0.9 \pm 0.1$ & $1.0 \pm 0.1$ & NS \\
\hline AMI $=24$-hour study for tollow-up subgroup; other abbreviations as in Iable ll. \\
\hline
\end{tabular}

acutely, but recovered by 1 week $(8.5 \pm 0.7 \mathrm{~cm}$ to 11.8 $\pm 1.1 \mathrm{~cm} ; \mathrm{p}<0.01)$ to that of control subjects. Similarly, early filling, as measured by velocity time integral 0.333 , and velocity time integral $E$ were depressed acutely $(3.5 \pm 0.4 \mathrm{~cm}$ and $5.1 \pm 0.5 \mathrm{~cm}$, respectively) and showed significant recovery after 7 days $(5.2 \pm 0.5$ $\mathrm{cm}, \mathrm{p}<0.01$ and $6.8 \pm 0.7 \mathrm{~cm}, \mathrm{p}<0.05$, respectively). Again, the follow-up values were not significantly different from coronary artery disease control subjects. There was no significant change in velocity time integral $\mathrm{A}$ from acute to follow-up examination.

Vclocity time integral $\mathrm{A} /$ total was lower at followup than it was acutely $(0.4 \pm 0.02$ vs $0.5 \pm 0.04)$, although statistical significance was not quite reached ( $p$ $=0.07$ ). Velocity time integral $0.333 /$ total increased significantly from the initial study to 7 days $(0.42 \pm$ 0.04 vs $0.45 \pm 0.03 ; p<0.05$ ) but velocity time integral $\mathrm{E} /$ total was unchanged. The peak velocities and velocity time integrals at 7 days were not significantly different from those of the coronary disease control group.

Serial measurements of global systolic function by radionuclide or contrast ventriculography were available in 14 of the 17 patients in the follow-up subgroup. There were no significant changes in ejection fraction from the first to the seventh day after infarction (initial mean $43.1 \pm 2.5 \%$ vs a follow-up mean of $45.4 \pm 3.0 \%$, $\mathrm{p}=0.57$ ).

Subgroup analysis was performed in the follow-up patients to compare anterior myocardial infarction versus inferior infarction and ejection fraction $>40 \%$ vs
FIGURE 1. Comparison of velocity time integrals of total diastolic filling (velocity time integral total), first third of diastole (velocity time integral 0.333), early filling (velocity time integral E) and late filling (velocity time integral A) in coronary disease control subjects versus acute myocardial infarction group. CAD = coronary artery disease control group; CM = centimeters; MI = acute myocardial infarction group; VTI = velocity time integral.

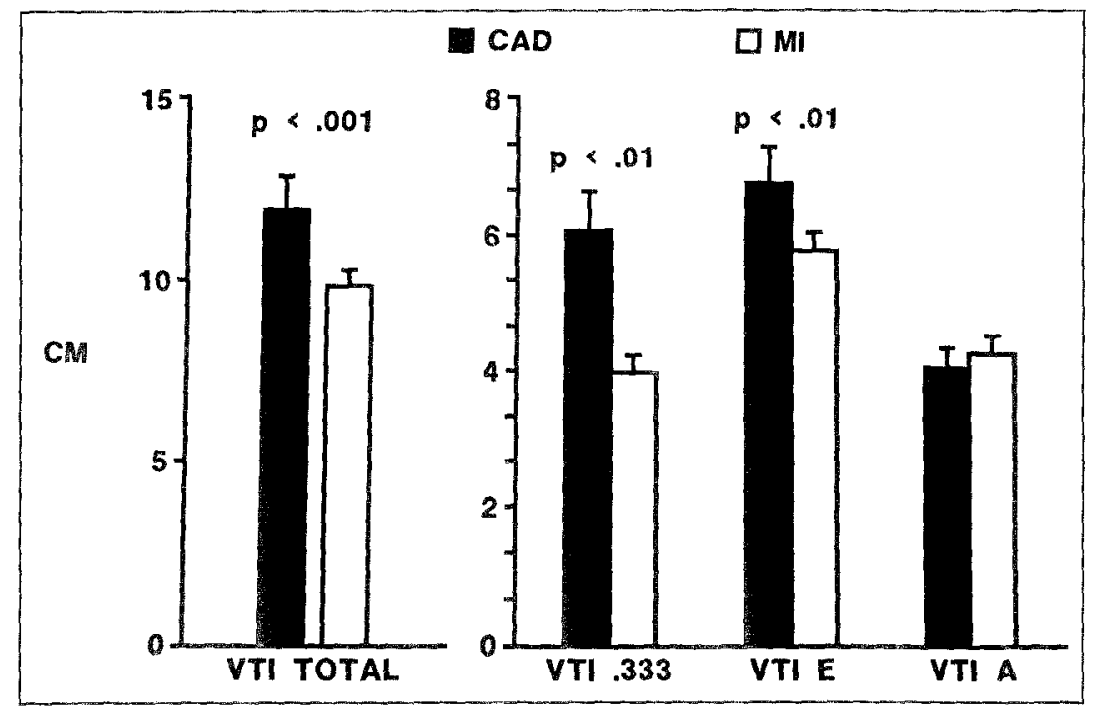




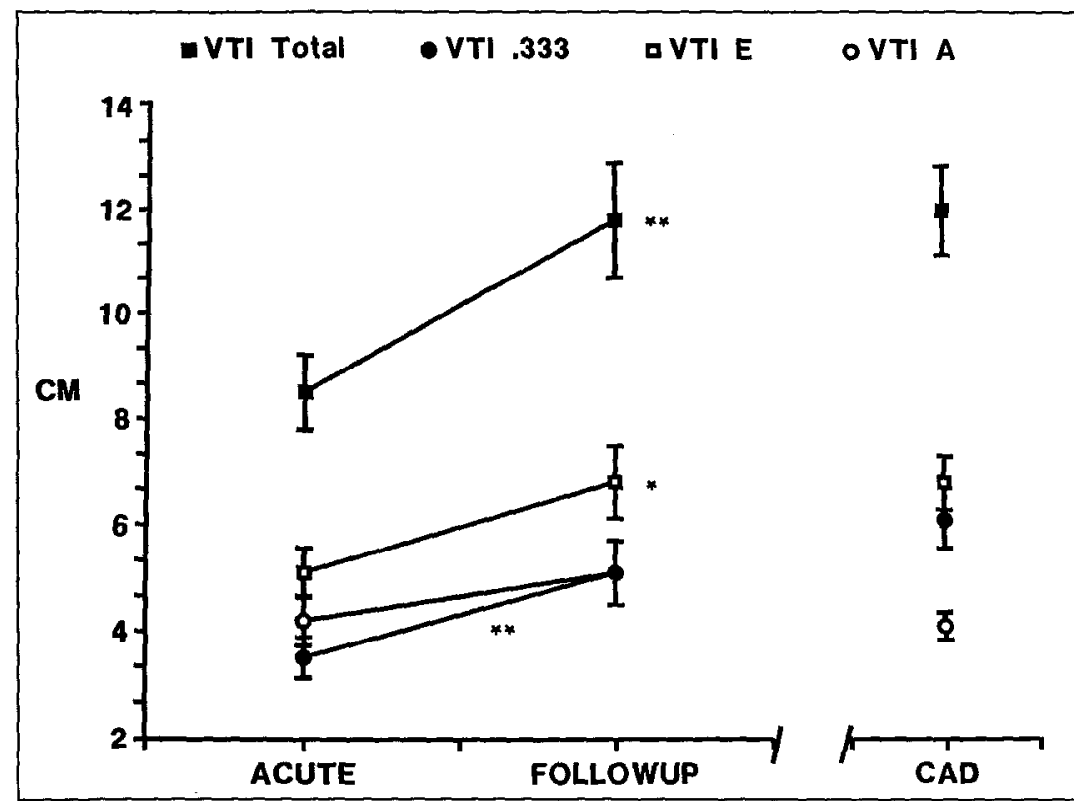

FIGURE 2. Velocity time integrals of total filling (velocity time integral total), first third diastole (velocity time integral

0.333 ), early filling (velocity time integral E) and late filling (velocity time integral A) at 24 hours and the 7 days after infarction. Values for the coronary artery disease control group are placed on right side of the graph for reference. *p $<0.05$ vs 24 hours; ** $<0.01$ vs 24 hours.

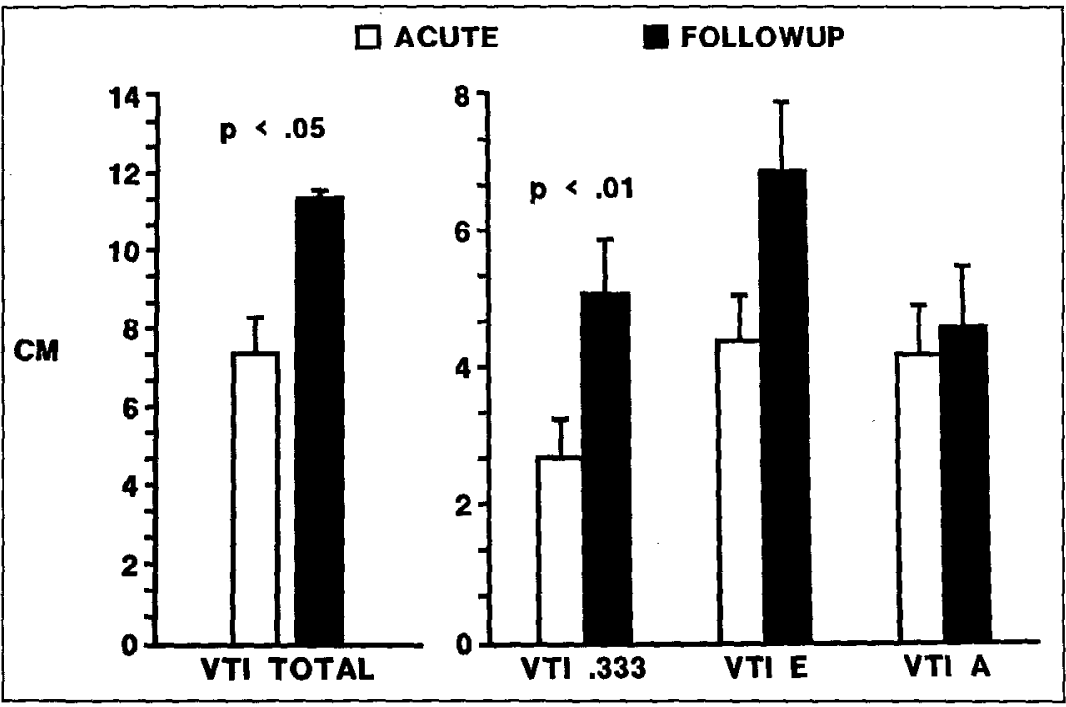

FIGURE 3. Comparison of velocity time integrals between acute and follow-up examinations in the subgroup of patients with anterior myocardial infarction.

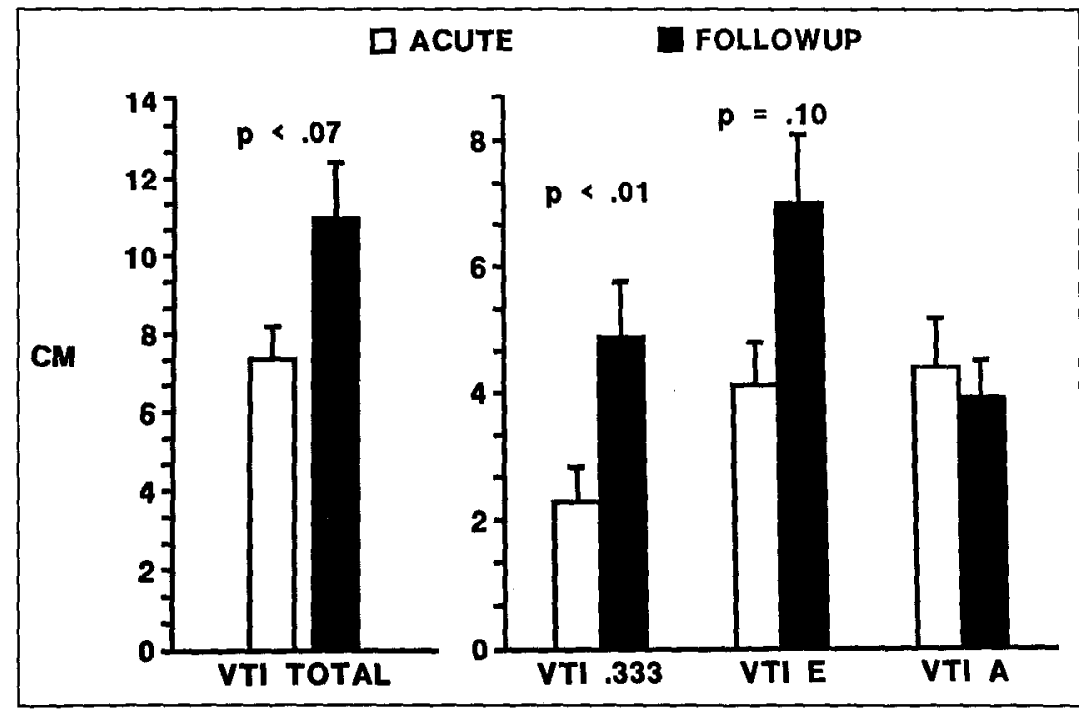

FIGURE 4. Velocity time integrals for the acute and follow-up examinations in patients with initial ejection fraction $<40 \%$. 
$<40 \%$. There was no significant change in hemodynamics over the week after infarction in the group as a whole, although patients with anterior infarction had a statistically significant change in heart rate over the 7 day follow-up period ( $89 \pm 4$ vs $78 \pm 3$ beats $/ \mathrm{min}$ respectively, $\mathrm{p}<0.01$ ). There were no significant changes in peak filling velocities over time, but in patients with anterior infarction, a significant improvement in velocity time integral total $(7.4 \pm 0.9 \mathrm{~cm}$ vs $11.4 \pm 1.6 \mathrm{~cm}$, $\mathrm{p}$ $<0.05)$ and velocity time integral $0.333(2.7 \pm 0.5 \mathrm{~cm}$ vs $5.1 \pm 0.8 \mathrm{~cm}, \mathrm{p}<0.01$ ) was seen (Figure 3 ). The patients with inferior infarction did not show significant changes in peak velocities or velocity time integrals.

Similarly, in the subgroup of patients with initial ejection fraction $<40 \%$, there was no change in hemodynamics or peak filling velocities. However, despite the limited number of patients, a significant improvement in early filling as measured by velocity time integral $0.333(2.4 \pm 0.5 \mathrm{~cm}$ vs $5.1 \pm 0.9 \mathrm{~cm}, \mathrm{p}<0.01)$ was seen in this subgroup of patients with initially impaired ejection fraction. Velocity time integral total and velocity time integral $\mathrm{E}$ showed trends to increase within 7 days, but statistical significance was not quite reached. These results are shown in Figure 4. Patients with initial ejection fractions that were $>40 \%$ did not show any significant changes in peak filling velocities or velocity time integrals over the first 7 days.

Sixteen of the 17 follow-up patients were successfully reperfused. Because of the high incidence of reperfusion in this group, subgroup analysis to compare filling parameters at follow-up based on reperfusion status was not possible.

\section{DISCUSSION}

Alterations in LV filling dynamics may be due to a variety of mechanisms, including changes in myocardial stiffness, impaired LV relaxation, changes in right ventricular loading conditions, pericardial constraints, viscoelastic considerations and nonuniformity, among others. ${ }^{11}$ Clearly, the determinants of diastolic filling are complex. The aim of this study was not to set apart the impact of these various forces, but to measure $\mathrm{LV}$ filling after AMI and the changes that occur in filling over time, as a reflection of possible recovery.

The important new observations from our study are the following: early diastolic LV filling after $\mathrm{AMI}$ is decreased, while the atrial contribution to filling is maintained; filling is most impaired initially in patients with anterior infarction or with more severely depressed cjcction fraction; and normalization of filling patterns occurs in the first week after AMI.

It is well known that myocardial ischemia can lead to impairment in systolic function, with regional wall motion abnormalities resulting in decreased ejection fraction and increased ventricular volumes. ${ }^{12}$ The impact of acute ischemia on diastolic properties has been less well defined. Several investigators have observed an upward shift in the pressure-volume curve with myocardial ischemia as a result of an increase in resistance to LV filling or increased chamber stiffness. ${ }^{13,14}$ These diastolic abnormalities during acute ischemia are further reflected by impairment in early $L V$ filling after transient coronary occlusion by angioplasty. ${ }^{4}$

Diastolic filling in coronary artery disease: In addition to these findings with acute ischemia, a number of studies have identified abnormal filling patterns in patients with stable coronary artery disease. Radionuclide angiography has shown that patients with coronary artery disease have impaired early peak LV filling rates at rest, independent of systolic function or previous AMI. These filling abnormalities have been shown to normalize after revascularization, either by angioplasty or coronary bypass surgery. ${ }^{15,16}$ Wind et al, ${ }^{9}$ using Doppler echocardiography, showed significantly depressed peak E (early diastolic) velocity in patients with stable coronary artery disease and normal global systolic function as well as an increased percentage of the Doppler LV filling during late diastole. These diastolic LV filling abnormalities persisted 24 hours after successful angioplasty. Thus ischemia, in the absence of AMI, can lead to prolonged abnormalities in early filling, with preservation of late filling due to atrial systole. In this study, diastolic LV filling was equally impaired acutely in patients who had been successfully reperfused and in those who had not. Although this impairment may be reversible, the time course and mechanism of such recovery is not well known.

Diastolic LV filling abnormalities have also been reported in patients with remote AMI. Fuji et al ${ }^{17}$ studied 40 patients with previous AMI and found prolonged deceleration and acceleration half-times of transmitral inflow, as well as an increase in late diastolic inflow relative to early filling, suggesting that weeks after AMI, early diastolic filling is impaired, which may be compensated for by atrial systole. Thus, these data, in combination with our own, may suggest that diastolic function initially is impaired after AMI, improves over the first 7 days, but then becomes further impaired as infarct healing and scarring occur. However, additional serial studies in patients after AMI will be necessary to support this hypothesis.

Other factors, such as hypertension, diabetes and mitral regurgitation, have been shown to affect filling dynamics. However, there was no difference in the incidence of these clinical parameters in the infarction patients and the control group.

Impact of reperfusion: The development of thrombolysis has provided the potential to change the natural history of AMI. The post-AMI period has been shown to result in dynamic changes with consequent myocardial remodeling and possible infarct expansion. The impact of thrombolysis and reperfusion on subsequent systolic and diastolic performance has only recently been addressed. ${ }^{18,19}$ Global and regional systolic function may be preserved both in experimental animals and in humans after infarction with reperfusion. ${ }^{20,21}$ However, little is known in humans concerning diastolic performance after acute ischemia and reperfusion. In this regard, our study provides new observations on changes in diastolic filling after reperfusion. Almost all patients in this study underwent successful reperfusion, which may have contributed to the improvement in filling dynamics 
over time. The percentage of patients who did not have successful reperfusion was too small to assess the differential impact reperfusion had on diastolic filling in the recovery period.

Few experimental studies have addressed the effect of reperfusion on diastolic performance. Kurnik et al ${ }^{6}$ examined the impact of AMI and reperfusion on myocardial and chamber stiffness in a canine model. They found coronary occlusion led to a decrease in LV systolic function and a concomitant increase in myocardial and chamber stiffness. One hour of occlusion with subsequent reperfusion resulted in improvement in systolic function and decreased stiffness by 1 week. On the other hand, late reperfusion or permanent occlusion resulted in persistent abnormalities in indexes of systolic and diastolic function. Tilton et $\mathrm{al}^{7}$ examined LV segmental relaxation in dogs undergoing a 2- or 4-hour coronary occlusion followed by reperfusion. They found that the recovery of diastolic function occurred in the first week after AMI. Thus, the findings of this experimental study concur with our clinical observations, which showed an improvement in diastolic filling over the first week after AMI.

Potential mechanisms: The determinants of diastolic filling are complex and cannot be differentiated in our study. However, 2 major mechanisms of impaired filling in the setting of AMI are decreased myocardial relaxation and increased LV stiffness. Decreased relaxation would be expected to have its greatest impact during early diastole, as the transition from active contraction to active relaxation occurs. ${ }^{22}$ Impaired relaxation after AMI appears to be due to depletion of adenosine triphosphate stores or changes in intracellular calcium concentration. ${ }^{23-25}$ Increased stiffness, while it may affect the slope of the pressure-volume curve throughout diastole, would tend to provide the greatest resistance to filling near end-diastole, at maximum ventricular distention. ${ }^{22}$ This increased stiffness may be secondary to edema formation early after AMI, or developing fibrosis in the late post-AMI course. ${ }^{26}$ Both of these mechanisms may play a role in contributing to observed diastolic filling abnormalities.

In addition to decreased myocardial relaxation and increased LV stiffness, there are a number of other factors that may also play a role in diastolic filling abnormalities. These include the production of reactive oxygen metabolites, which have been shown to interfere with sarcoplasmic reticulum function, extrinsic factors such as pericardial constraints and right ventricular loading conditions, and temporal nonuniformity of relaxation. Clearly, further investigation will be necessary to delineate the contributions of these multiple factors.

Recent experimental models have shown that postischemic reperfused myocardium exhibits abnormalities in diastolic as well as systolic performance, which may be prolonged but which have the potential for recovery. 7.27 These findings have been proposed to reflect stunning of both systolic and diastolic properties (i.e., sublethal ischemic injury to myocardial cells results in functional abnormalities, which may be reversible once flow is restored). Our clinical findings are consistent with the hypothesis of stunning of diastolic function after ischemic injury with recovery after reperfusion.

The decrement in total filling observed in this study may also be related to changes in cardiac output, since concomitant changes in systolic performance occur after AMI. ${ }^{27}$ However, the overall pattern of diastolic filling changed with infarction, with the predominate impact on filling occurring during early diastole, which normalized in the recovery period. This differential change in the pattern of $\mathrm{LV}$ filling suggests a concomitant abnormality in diastolic performance. Furthermore, the changes in diastolic filling that occurred during the first week after AMI were not accompanied by improvement in systolic function measured by ejection fraction. Thus, our study supports the concept that perturbations in systolic and diastolic function are tightly interrelated and that ischemia results in a global stunning of myocardial performance with gradual recovery after reperfusion.

Study limitations: Several studies have shown the effect preload can have on filling dynamics. ${ }^{28.29}$ Decreased preload, such as by occlusion of the vena cava or by intravenous nitroglycerin decreases peak early filling, whereas increased preloäd via volume infusion augments early filling. ${ }^{30}$ In general, one might expect higher filling pressures after infarction, which would have augmented early filling, which was the opposite of our findings. Thus, it seems unlikely that the changes we observed can be accounted for by changes in preload. However, since invasive hemodynamic correlates were not available in all of our patients, changes in preload affecting early diastolic filling cannot be excluded. Heart rate can also alter diastolic filling. Although there was a trend toward higher heart rates initially after AMI, it was not statistically significant. In the subgroup of patients with anterior AMI, heart rate significantly decreased within 1 week, although the AMI group as a whole, as well as other subgroups, did not have significant changes in heart rate with serial examinations. Thus, it is unlikely that the changes in filling that we observed can be explained by these other factors.

Acknowledgment: We sincerely appreciate the contributions of Dr. Rita C. Pinton and Dr. A. Rebecca Snider to the study. We would also like to thank Mary Sue LeMire and Maria Bajor for their technical assistance during the study.

\section{REFERENCES}

1. Ginks WR, Sybers HD, Maroko PR, Covell JW. Sobel BE, Ross J Jr. Coronary artery reperfusion. Il. Reduction of myocardial infarct size at I week after occlusion. J Clin Invest 1972:51:2717-2723

2. Kloner RA, Fllis SG, Lange R, Braunwald E. Studies of experimental coronary artery reperfusion: effects on infarct size, myocardial function, biochemistry. ultrastructurc and microvascular damage. Circulation 1983;(suppl 1) 68:1-8.

3. Braunwald $\mathrm{E}$, Kloner RA. The stunned myocardium: prolonged, postischemic ventricular dysfunction. Circulation 1982;66:1146 1149 .

4. Bruyne B, Lerch R, Meier B, Schlaepfer II, Gabathuler J, Rutishauser W Doppler assessment of Icft ventricular diastolic filling during brief coronary occlusion. Am Heart J 1989:117:629-635.

5. Visser CA, David GK, Kan G, Romijn KH, Meltzer RS, Koolen JJ, Dunning 
AJ. Two-dimensional echocardiography during percutaneous transluminal coronary angioplasty. Am Heart $J$ 1986;111:1035-1041.

6. Kurnik PB, Courtvis MR, Ladbrook PA. Diastolic stiffening induced by acute myocardial infarction is reduced by early reperfusion. $J \mathrm{Am}$ Coll Cardiol 1988;12:1029-1036.

7. Tilton GD, Bush LR, Apprill PG, Buja LM, Willerson JT. Effect of diltiazem and propranolol on left ventricular. segmental relaxation during temporary coronary arterial occlusion and one month reperfusion in conscious dogs. Circulation 1985;71:165-175.

8. Spirito P, Maron BJ, Bonow RO. Noninvasive assessment of left ventricular distolic function: comparative analysis of Doppler, echocardiographic and radionuclide angiographic techniques. J Am Coll Cardiol 1986;7:518-526.

9. Wind BE, Snider AR, Buda AJ, O'Neill WW, I'opol EJ, Dilworth LR. Pulsed Doppler assessment of left ventricular diastolic filling in coronary artery disease before and immediately after coronary angioplasty. Am J Cardiol 1987;59:10411046.

10. Snider AR, Gidding SS, Rochini AP, Rosenthal A, Dick M. Crowley DC, Peters J. Doppler evaluation of left ventricular diastolic filling in children with systemic hypertension Am I Cardiol 1985:56:921-926.

11. Grossman W. Relaxation and diastolic distensibility of the regionally ischemic left ventricle. In: Grossman W, Lorrell B, eds. Diastolic Relaxation of the Heart. Boston: Martinus Nijhoff, 1988:193-203.

12. Seals A, Pratt CM, Mahmarian JJ, Tadros $S$, Keiman N, Roberts R, Verani MS. Relation of left ventricular dilation during acute myocardial infarction to systolic performance, diastolic dysfunction, infarct size and location. Am J Cardiol 1988:61:224-229.

13. Carroll JD, Hess GM, Hirzel HO, Enuehl HP. Exercise-induced ischemia: the influence of altered relaxation on early diastolic pressures. Circulation 1983;67:521-527.

14. Bourdillon PD, Lorell BH, Mirsky I, Paulus WJ, Wynne J, Grossman W. Increased regional myocardial stiffness of the left ventricle during pacing-induced angina in man. Circulation 1983;67:316-323.

15. Bonow RO, Kent RM, Rosing DR, Lipson LC, Bacharach SL, Green MV, Epstein SE. Improved left ventricular diastolic filling in patients with coronary artery disease after percutaneous transluminal coronary angioplasty. Circulation 1982;66:1159-1167.

16. Carroll JD, Hess GM, Hirzel HO, Turina M, Krayenbuehl HP. Left ventricular systolic and diastolic function in coronary artery disease: effects of revascularization on exercise-induced ischennia. Circulation 1985;75:119-129.

17. Fuji J, Yazaki Y, Sawada H, Aizawa T, Watanabe H, Kato K. Noninvasive assessment of left and right ventricular filling in myocardial infarction with a twodimensional Doppler echocardiographic method. J Am Coll Cardiol 1985;5: $1155-1160$

18. Lavallee M, Cox D, Patrick TA, Vatner SF. Salvage of myocardial function by coronary artery reperfusion 1,2 , and 3 hours after occlusion in conscious dog. Circ Res 1983;53:235-247.

19. Kennedy JW, Ritchie JL, Davis KB, Fritz JK. Western Washington randonized trial of intracoronary streptokinase in acute myocardial infarction. $N$ Engl $J$ Med 1983:309:1477-1482.

20. Stack RS, Phillips HR IIl, Grierson DS, Behar VS, Kong Y, Peter RH, Swain JL, Greenfield JC Jr. Functional improvement of jeopardized myocardium following intracoronary streptokinase infusion in acute myocardial infarction. $J$ Clin Invest 1983;72:84-95.

21. Topol EJ, Bates ER, Walton JA Jr, Baumann G, Wolfe S, Maino J, Bayer L, Gorman L, Kline EM, O'Neill WW. Community hospital administration of intravenous tissue plasminogen activator in acute myocardial infarction: improved timing, thrombolytic efficacy and ventricular function. $J \mathrm{Am}$ Coll Cardiol 1987;10:1173-1177

22. Stoddard MF, Pearson AC, Kern MJ, Ratcliff J, Mrosek DG, Labovitz AJ Left ventricular diastolic function: comparison of pulsed doppler echocardiographic and hemodynamic indexes in subjects with and without coronary artery disease. I Am Coll Cardiol 1989;13:327-336.

23. Fllis SG, Henschel CI Sandor T Wynne J, Braunwald E, Kloner RA Time course of functional and biochemical recovery of myocardium salvage by reperfusion. J Am Coll Cardiol 1983;1:1047-1055.

24. Monomura S, Ingwall JS, Parker H, Schagian P, Ferguson JJ, Grossman W. The relationships of high energy phosphates, tissue $\mathrm{pH}$ and regional blood flow to diatolic distensibility in the ischemic dog myocardium. Circ Res 1985;57:822835 .

25. Henry PD, Shuchleib R, Davies J. Weiss ES, Sobel BE. Myocardial contracture and accumulation of mitochondrial calcium in ischemic rabbit heart. $A m J$ Physiol 1977;233:H677-H684.

26. Paulus WJ, Scrizwa T, Grossman W Altcred left ventricular diastolic properties during pacing-induced ischemia in dogs with coronary stenoses: potentiation by caffeine. Circ Res 1982;50:218-227.

27. Charlat ML, O'Neill PG, Hartley C.I, Roberts R, Bolli R. Prolonged abnormalities of left ventricular diastolic wall thinning in the "stunned" myocardium in conscious dogs: time course and relation to systolic function. $I \mathrm{Am} \mathrm{Coll} \mathrm{Cardiol}$ $1989 ; 13: 185-193$

28. Choong CY, Herrmann HC, Weyman AE, Fïfer MA. Preload dependence of Doppler-derived indexes of left ventricular diastolic function in humans. $J \mathbf{A m}$ Coll Cardiol 1987;10:800-808.

29. Ishida Y, Meisner JS, Tsujioka K, Gallo JI Yoran C, Frater RW Yellin EL. Left ventricular filling dynamics: influence of left ventricular relaxation and left atrial pressure. Circulation 1986;74:1987-1996.

30. Courtois MA, Vered Z, Barzilai B, Ricciotti NA, Perez JE, Ludbrook PA. The transmitral pressure-flow velocity relation: effect of abrupt preload reduction. Circulation 1988;78:1459-1468. 